\title{
STUDY ON SPATIAL-TEMPORAL VARIATION OF HONG LAKE BASED ON VIIRS AND MODIS IMAGES
}

\author{
LI Congzheng ${ }^{1}$ ZHONG Yanmei ${ }^{2}$ ZHANG Wen ${ }^{3}$ \\ ${ }^{1}$ School of Remote Sensing Information Engineering, Wuhan University, Wuhan Hubei, China 430079, congzhengli@qq.com \\ ${ }^{2}$ School of Remote Sensing Information Engineering, Wuhan University, Wuhan Hubei, China 430079, 820724471@ @q.com \\ ${ }^{3}$ School of Remote Sensing Information Engineering, Wuhan University, Wuhan Hubei, China 430079, wen_zhang@ whu.edu.cn
}

KEY WORDS: VIIRS, MODIS, Hong Lake, NDWI, change monitoring

\begin{abstract}
:
Hong Lake is the largest lake in Hubei Province. With the increase of Hong Lake economic activity, the area, spatial location and shape of Hong Lake have changed greatly in the past. In this paper, we used the images, which is from the visible infrared imaging radiometer (VIIRS). First, we selected the images of Hong Lake waters on December 6, 2016 and December 26, 2015. Then we extracted the water bodies by the single-band method, spectral relationship method, normalized difference water index (NDWI) were used, and the effect-s were compared. Second, the images of Hong Lake waters in summer and winter were selected from 2012 to 2016, respectively. Last, The NDWI was used to extract the water body and compared with the MODIS image extraction effect in the same period. As a result of the vegetation around Hong Lake, the water is extracted by NDWI and normalized difference vegetation index $(N D V I)$. It is found that for the VIIRS image, the $N D W I$ is the best in the water extraction of Hong Lake. The $N D V I+N D W I$ method is beneficial to the extraction of water covered with aquatic plants. VIIRS image extraction is better than MODIS image. In addition, from the study of VIIRS and MODIS to Hong Lake waters in the five years of water extraction and area calculation, 20122016 period, Hong Lake's average area of $348.213 \mathrm{~km}^{2}$ in flood season, in dry season average area of $349.163 \mathrm{~km}^{2}$. The largest area for the 2012 flood season $389.751 \mathrm{~km}^{2}$, the smallest area of 2016 flood season $306.177 \mathrm{~km}^{2}$. Overall, Hong Lake's area changes little.
\end{abstract}

\section{INTRODUCTION}

The data from MODIS (moderate-resolution imaging spectroradiometer) which was carried Terra satellite platform and launched in 1999, are widely used in agricultural disaster monitoring, atmospheric and water monitoring because of its advantages such as free reception, large observation ranges and short repetition cycle. However, because the MODIS sensor's service life designed has been exceeded, and the sustainable risk of MODIS data has been increased. In October 28, 2011, NASA launched the next generation earth observation satellite--Suomi National Polar-orbiting Partnership (Suomi NPP) for replacing the earth observation mission of Terra, Aqua and Aura satellite. NPP carried a new generation of earth observation sensor which was used to replace the MODIS satellite. Visible infrared imager radiometer suite (VIIRS) inherits and develops in MODIS, and is certainly similar to the MODIS sensor. Therefore, studying extraction water and plants based VIIRS data is beneficial to the smooth transition of MODIS data to VIIRS data. VIIRS data can be used to measure cloud cover and aerosol characteristics, ocean's colour, ocean and land surface temperatures, sea ice movement and temperature, fire, and albedo and so on.

Hong Lake, the largest lake in Hubei and the seventh largest freshwater lake in China, is located in the middle reaches of the Yangtze River, downstream of the four lake river. It is also one of the 238 most important ecological areas around the world, the water area about $400 \mathrm{~km}^{2}$ in normal year, and known as the kidney of central south. In 2012, Wen Xiongfei used Landsat images to study Hong Lake and found that the surrounding lakes are cultivated by fishermen, and preliminary analysis showed that the water area of Hong Lake was related to rainfall. Liu Xinghong pointed out that the factors of Hong Lake water area affected by the climate change, aquaculture and "Wei Hu Zao Tian" etc. Sun Chuang and others studied the use of water in Hong Lake by using RS and GIS. It was found that due to the influence of human activities, the surface area of Hong Lake showed a decreasing trend. Yet there is no one using MODIS or VIIRS images to study lakes, so in this research, we use remote sensing processing technology to study extraction and monitoring the changes of Hong Lake water by VIIRS images. For VIIRS, it is a good attempt to be used to extract and monitor water bodies. It also provides a good example for remote sensing monitoring of water surface.

\section{MATERIALS AND METHODS}

\subsection{Overview of the study area}

In this study, the scope of the administrative divisions of Hong Lake city and Jianli county is taken as the study area. The location of Hong Lake is $113^{\circ} 12^{\prime} \mathrm{E} \sim 113^{\circ} 26^{\prime} \mathrm{E}, 29^{\circ} 40^{\prime} \mathrm{N} \sim 29^{\circ} 58^{\prime} \mathrm{N}$. The lake area is $355 \mathrm{~km}^{2} \sim 413 \mathrm{~km}^{2}$, distance from east to west is $23.4 \mathrm{~km}$, north from south is $20.8 \mathrm{~km}$, the bottom elevation is about $22.5 \mathrm{~m}$, the average water depth is $1.35 \mathrm{~m}$, the maximum water depth is $2.32 \mathrm{~m}$, the minimum water depth is $0.4 \mathrm{~m}$. Hong Lake watershed is low-lying terrain, surrounded by the Yangtze River, Hanjiang River and the East Jing River in three directions respectively. And Hong Lake drainage and storage water by a number of culverts through the Yangtze River on the lake water discharge and regulation. Hong Lake is a subtropical humid monsoon climate, which is characterized by long winter and summer, and short spring and autumn, four distinct seasons, adequate light, abundant rainfall, mild and humid, hot summer and cold winter, precipitation concentrated in the spring and summer, floods more. Hong Lake watershed annual average temperature is about $16.6^{\circ} \mathrm{C}$. Perennial coldest month is in January and the average temperature is $3.8^{\circ} \mathrm{C}$ and hot months is July and August, which average temperature is $28.9^{\circ} \mathrm{C}$. Hong Lake average sunshine 
usually is between 1980 2032 hours, average annual rainfall is 135.7 days and rainfall varies $1060.5 \mathrm{~mm}$ from $1331 \mathrm{~mm}$. Summer rainfall is generally increasing, 4 9 months of rainfall accounts for is about $74 \%$ of annual rainfall. The study area is shown in Figure1:

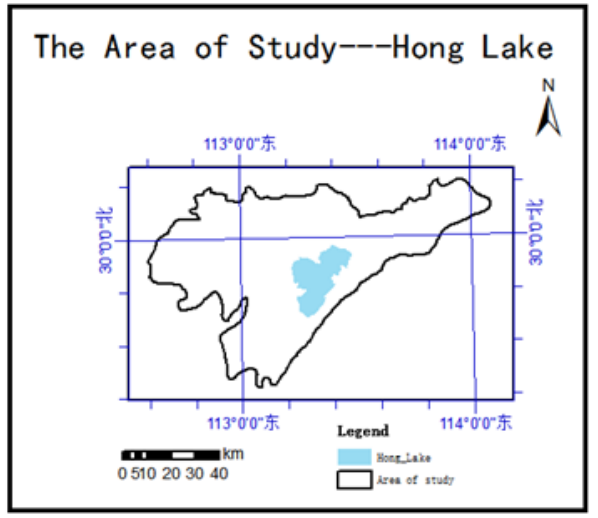

Figure1: The area of study.

\subsection{Data sources}

2.2.1 Introduction of VIIRS data: VIIRS sensor has a total of 22 bands, including 5 images with a resolution of $375 \mathrm{~m}$, one DNB band with resolution of $750 \mathrm{~m}, 16$ visible and infrared channels with a resolution of $750 \mathrm{~m}$.VIIRS's scanning angle is $\pm 56^{\circ}$, its observation range reach $3000 \mathrm{~km}$, which in general is more similar to MODIS sensor.

The most prominent feature of VIIRS relative to MODIS sensors is the effective control of the spatial resolution that increases as the scanning angle increases, and this is VIIRS improvement on the polar orbit satellite data quality. VIIRS data can be used to measure cloud and aerosol properties, ocean's color, ocean and land surface temperatures, sea ice movements and temperatures, fires, and earth albedo etc.

2.2.2 research data Introduction: In this study, date was downloaded the 2012 2016 summer and winter cloudless or little cloudy volume of the VIIRS and MODIS images from NOAA's official website. The selected dates are as follows:

\begin{tabular}{|c|c|c|}
\hline & VIIRS & MODIS \\
\hline \multirow{5}{*}{ Summer } & 2016/8/18 & $2016 / 8 / 28$ \\
\hline & $2015 / 8 / 3$ & $2015 / 8 / 3$ \\
\hline & $2014 / 8 / 7$ & 2014/10/7 \\
\hline & $2013 / 8 / 9$ & 2013/9/18 \\
\hline & $2012 / 8 / 8$ & $2012 / 8 / 8$ \\
\hline \multirow{5}{*}{ Winter } & $2016 / 12 / 6$ & $2017 / 1 / 22$ \\
\hline & $2015 / 12 / 26$ & $2015 / 12 / 26$ \\
\hline & $2014 / 12 / 7$ & $2014 / 12 / 19$ \\
\hline & 2013/12/1 & $2014 / 1 / 7$ \\
\hline & $2013 / 1 / 25$ & $2013 / 1 / 25$ \\
\hline
\end{tabular}

Table.1 selection schedule of study data

Because of MODIS and VIIRS's transit time is different, in the selection of MODIS images, the time is not strictly correspond. Where VIIRS image downloaded is $16 \mathrm{M}$-band and 5 I-band sensor data, and MODIS download is L1B image.

\subsection{Research methods}

Due to water, land and other objects on the solar radiation there are different reflection, absorption and transmission characteristics, so the imaging conditions on the remote sensing images are different. On remote sensing images, the boundary between the water and land is obvious and the lake boundary is easy to be recognized. There are many methods of water extraction based on remote sensing image, which can be summarized as two kinds: single-band threshold method and spectral relation method. However, in summer, due to the growth of vegetation around the waters, the extraction of water was effected. In this paper, we combines $N D V I$ and $N D W I$ to extract water, it's $N D V I+N D W I$.

2.3.1 Single-band threshold method: The basic principle of single-band threshold method is to use the reflectivity of water bodies in the near-infrared band is low, and easy to distinguish with other features, select a single infrared band, to determine a distinction between water and other geographical classification threshold. The advantages of threshold method to identify water is simple and rapid, easy to achieve. The key to this method is the determination of the threshold. The Near infrared band and wavelength of the VIIRS image are as follows: M7 $(0.865 \mu \mathrm{m})$, M8 $(1.24 \mu \mathrm{m}), \mathrm{M} 9(1.38 \mu \mathrm{m}), \mathrm{M} 10(1.61 \mu \mathrm{m}), \mathrm{M} 11(2.25 \mu \mathrm{m}), \mathrm{I} 2$ $(0.865 \mu \mathrm{m}), \mathrm{I} 3(1.61 \mu \mathrm{m})$. In this paper, we selected single-band threshold water extraction from December 6, 2016 and December 26, 2015, and as shown in Table 2, selected values for different time and different band thresholds. In the course of the study, the choice of the threshold is based on the idea of dichotomy, that is, first select the larger and smaller two thresholds, and then a larger and smaller average as the next effect, according to the extraction effect to determine the average and large thresholds or smaller thresholds are averaged until the extraction effect meets the requirements.

\begin{tabular}{|l|cc|}
\hline \multirow{2}{*}{ Bands } & \multicolumn{2}{|c|}{ Date } \\
\cline { 2 - 3 } & $2016-12-06$ & $2015-12-26$ \\
\hline M7 $(0.865 \mu \mathrm{m})$ & 1425 & 1375 \\
M8 $(1.24 \mu \mathrm{m})$ & 1075 & 1075 \\
M9 $(1.38 \mu \mathrm{m})$ & 1125 & 1092 \\
M10 $(1.61 \mu \mathrm{m})$ & 1225 & 1375 \\
M11 $(2.25 \mu \mathrm{m})$ & 1175 & 1250 \\
I2 $(0.865 \mu \mathrm{m})$ & 1072 & 1105 \\
I3 $(1.61 \mu \mathrm{m})$ & 625 & 725 \\
\hline
\end{tabular}

Table. 2 Threshold selection for single-band threshold method

2.3.2 spectral relationship method: The spectral relationship method is used to perform arithmetic operations on multiple bands to highlight some information and to suppress other information and to widen the distinction between features. Such as ratio method, difference method and water body index method.

1)Multi-band average threshold method: In the study process of study single-band threshold method, as the VIIRS image near infrared band range is rich, a total of eight bands, the multi-band mean threshold method is proposed on the basis of single-band threshold method, which will meet the average of the studied band, and then according to the selected image to select the appropriate value for classification, which is averaging the studied band, and then selecting the appropriate value for classification according to the selected image. 
2) normalized difference water index $(N D W I): N D V I$ is used to enhance the contrast between certain features by the ratio operation among bands, which is placing the strongest reflection band in the molecular position and the weakest reflection band in the denominator and can thus expand the difference between the two bands. In this way, the studied features in the newly generated image will get the maximum brightness so that the other features will be correspondingly suppressed and the studied features can be identified from the background. Since the value of NDWI calculation is very small, which is not suitable for the selection of the classification threshold, $N D W I$ is expanded by 10000 times during this study. The model formula is:

$$
N D W I=\frac{p_{\text {Green }}-p_{N I R}}{p_{\text {Green }}+p_{N I R}} \times 10000
$$

where $\quad N D W I=$ value of normalized difference water index $p_{\text {Green }}=$ VIIRS's M4 band; MDIOS's band 3 $p_{\text {NIR }}=$ VIIRS I3 band; MODIS's band 5

2.3.3 Normalized Difference Vegetation Index(NDVI): Because of the large number of aquatic plants planted around Hong Lake, the lakeshore of Hong Lake is easy to be covered by aquatic vegetation in summer, which affects the extraction of water bodies. In this paper, $N D V I$ and $N D W I$ are both introduced for water extraction. $N D V I$ model formula:

$$
N D V I=\frac{p_{N I R}-p_{R}}{p_{N I R}+p_{R}} \times 10000
$$

where $\quad N D V I=$ value of normalized difference vegetation index

$$
p_{R}=\text { VIIRS's M5band; MODIS's band } 1
$$

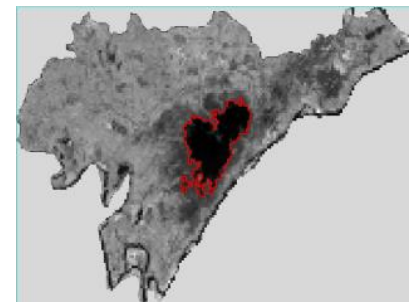

a. 2016-12-06 Band I3 (625)

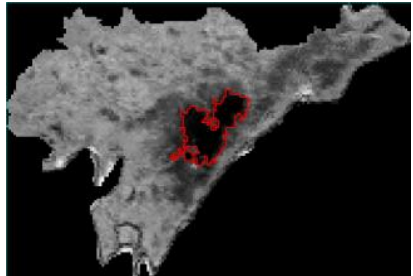

e. 2015-12-26 Band I3 (858)

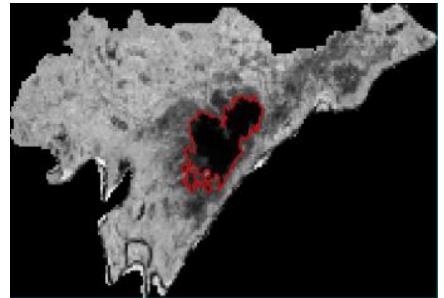

b. 2016-12-06 Band average (1082)

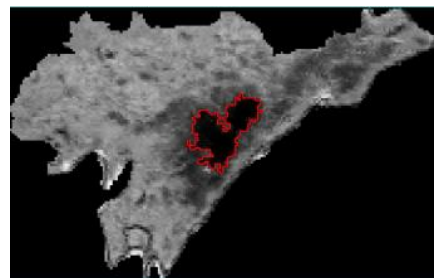

f. 2015-12-26 Band average (920)

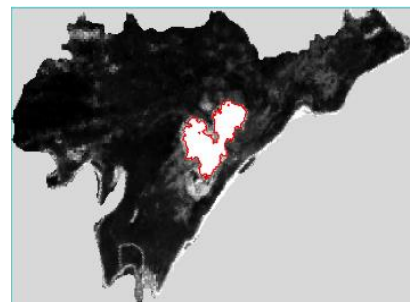

c. $2016-08-18$ NDWI (188)

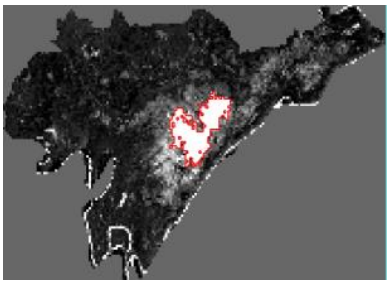

g. 2015-08-03 NDWI (8545)

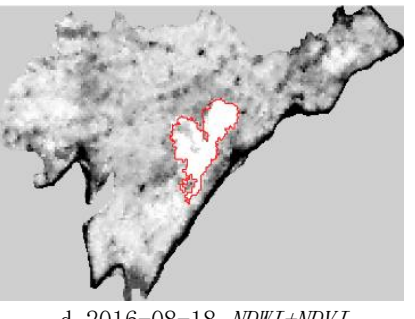

d. 2016-08-18 NDWI+NDVI

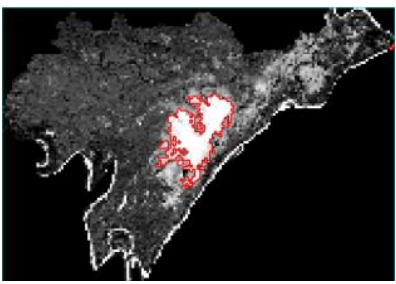

h. 2015-08-03 NDWI+NDVI

Figure2: The extract water effects comparison on December 26, 2015 and December 6, 2016 VIIRS images in different water extraction methods and different thresholds, where the values in parentheses represent thresholds.

\subsection{Comparison of VIIRS and MODIS in extracting water body}

After comparing the water extraction effect of VIIRS image with different methods, this paper selected two images of MODIS and VIIRS on August 8, 2012 and August 3, 2015 respectively. We tried to compare the two kinds of sensors advantages and disadvantages in extracting water. The comparison between the two shown in Figure 3. As shown in the figure, $N D W I+N D V I$ can be used to extract vegetation cover water for VIIRS images. MODIS images can be used to extract vegetation cover water by NDVI-NDWI method. In the process of extracting water, MODIS images appear to extract the region irregular, and the boundary appears obvious convex part, as shown in a, b of Figure 3. VIIRS image extraction of water under normal circumstances is relatively smooth, as shown in c, d of Figure 3. For the two kinds of spatial resolution is low, the extracted water body edge has obvious jagged, and low precision, compared to MODIS, VIIRS higher accuracy. As the VIIRS sensor is improved, the resulting 
image is relatively stable, and the extraction effect is relatively good, the accuracy is more stable.

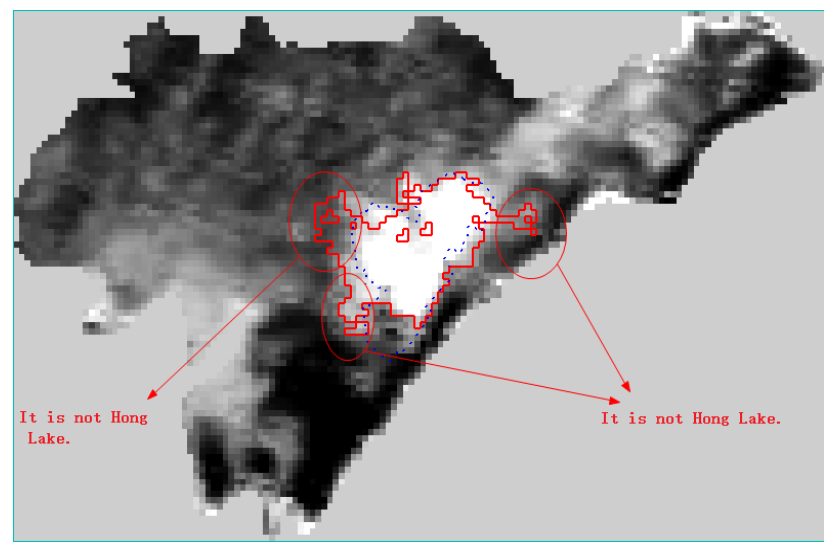

a.2012-08-08, MODIS, NDVI-NDWI

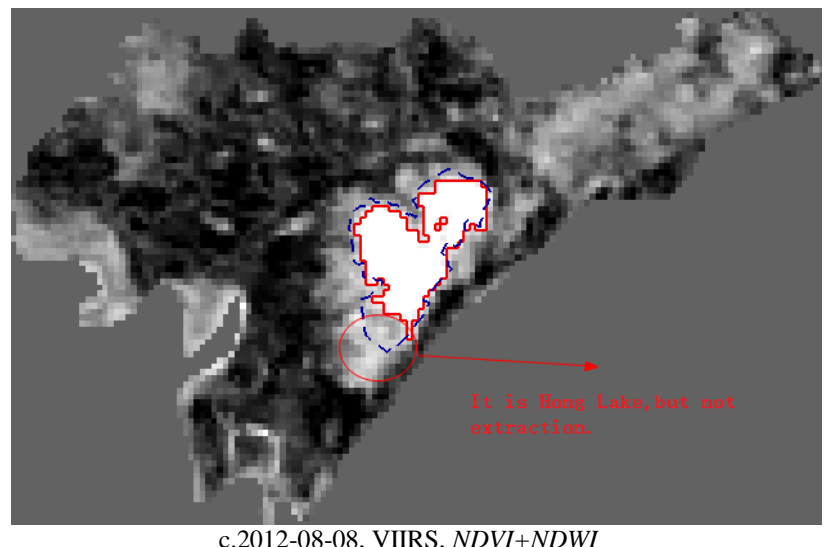

c.2012-08-08, VIIRS, NDVI+NDWI

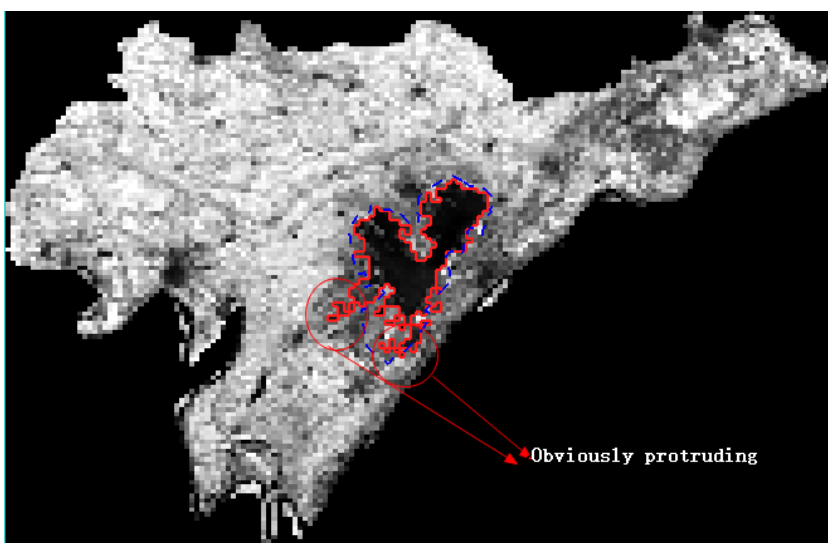

b.2015-08-03, MODIS, NDVI-NDWI

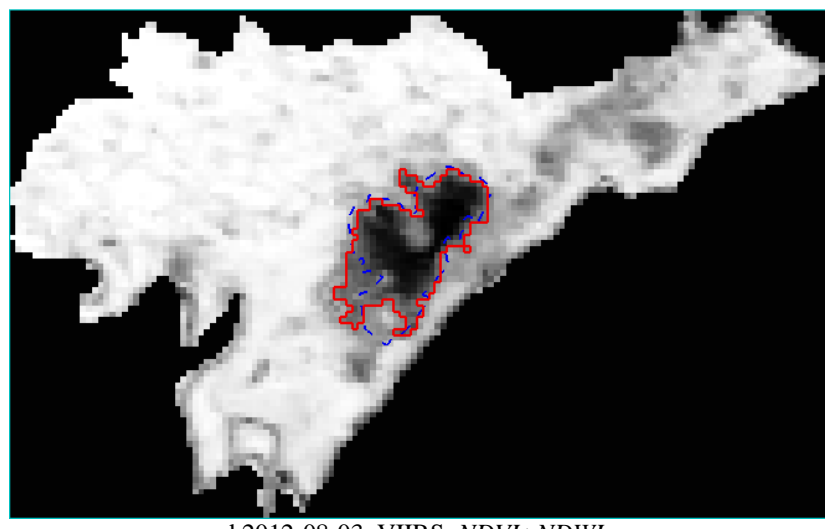

d.2012-08-03, VIIRS, $N D V I+N D W I$

Figure 3. Comparison of VIIRS Images and MODIS Images in Extracting Water.

\subsection{Extraction of lake information}

Compared with the above three methods, we directly extract water with $N D W I$ in the winter; while combined with both $N D W I$ and NDVI in the summer. In the extraction process, the classification results are transformed into vector by the use of
ENVI software and then processed to remove the lake central hole. The lake central hole is due to poor image quality leading to cloudy or other noise. After reviewing the relevant information of Hong Lake, Hong Lake central is no island in fact, so need to be removed. For the summer, merging with NDWI and NDWI + $N D V I$ extracted water vector to get Hong Lake range. Change of Hong Lake waters during 2012 2016 as follow Figure4.
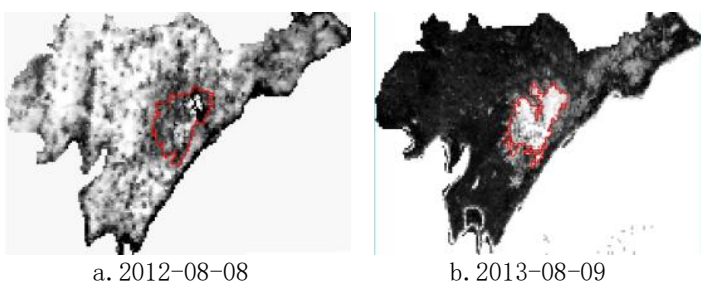

b. $2013-08-09$

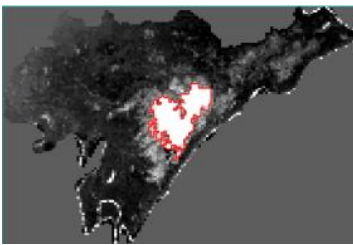

f. 2013-01-25

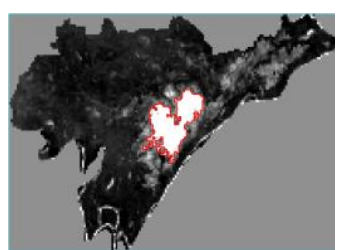

g. 2013-12-01

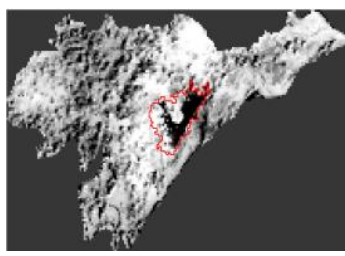

c. $2014-08-07$

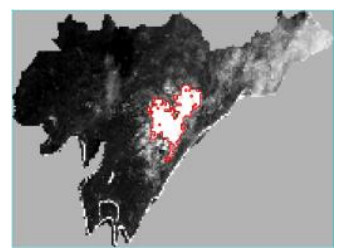

h. $2014-12-07$

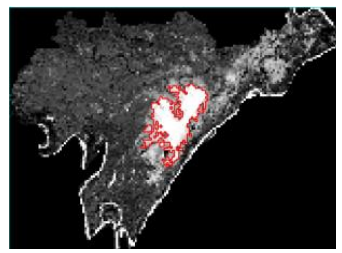

d. $2015-08-03$

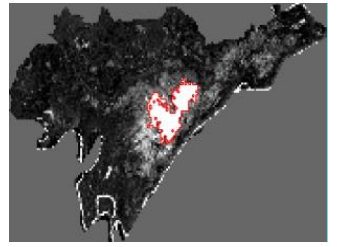

i. $2015-12-26$

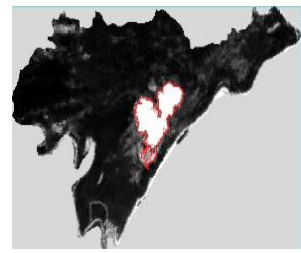

e. $2016-08-18$

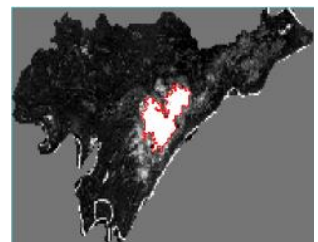

j. 2016-12-06

Figure4: The area changing of Hong Lake's comparison by using NDVI and NDWI method to extract from 2012 to 2016, the date of each chart under the picture represents the date of corresponding figure 


\subsection{Analysis of lake changes}

The extracted lake vector is opened in ArcMap software, the tool is used to transform the vector data to the
WGS_1984_UTM_Zone_49N projection coordinate system, and the vector area is calculated to obtain the area of each lake. In the selected dates, 2012 2016 using VIIRS images and MODIS images extracted Hong Lake area as shown in Table 3.

\begin{tabular}{|llll|}
\hline & Date & VIIRS & MODIS \\
\hline \multirow{3}{*}{ Flood season } & $2016 / 8 / 18$ & 306.1771 & 434.567 \\
& $2015 / 8 / 3$ & 362.183 & 449.254 \\
& $2014 / 8 / 7$ & 318.137 & 362.464 \\
Average area & $2013 / 8 / 9$ & 364.816 & 360.977 \\
& $2012 / 8 / 8$ & 389.751 & 278.684 \\
Dry season & $2016 / 12 / 6$ & 348.213 & 377.189 \\
& $2015 / 12 / 26$ & 327.244 & 356.577 \\
& $2014 / 12 / 7$ & 385.188 & 404.905 \\
Average area & $2013 / 12 / 1$ & 334.254 & 439.663 \\
& $2013 / 1 / 25$ & 342.336 & 475.262 \\
& & 356.793 & 454.535 \\
\hline
\end{tabular}

Table3: Extraction of Hong Lake's area by VIIRS and MODIS in 2012 2016(units:km²)

The average area of Hong Lake water extracted from VIIRS and MODIS is compared with that of Sun Chuang. It is found that VIIRS image extraction is more advantageous than MODIS when calculating area of water. From the Hong Lake surface area

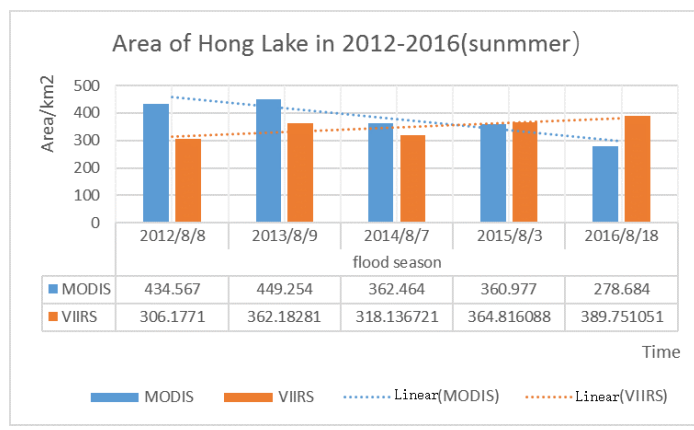

a. Hong Lake flood season area chart

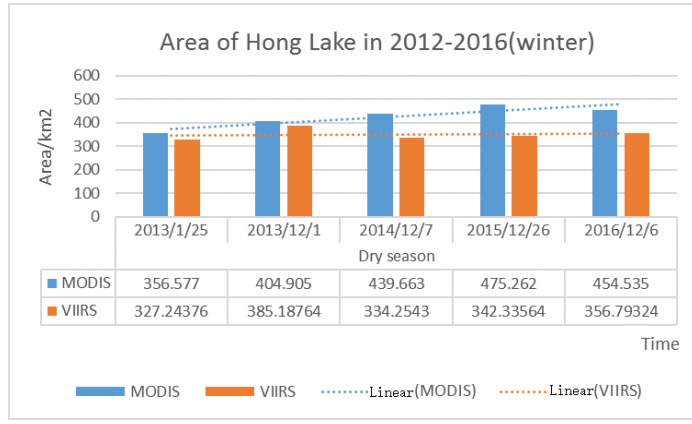

c. Hong Lake dry season area chart statistics, during 2012 2016, the average area of Hong Lake is $348.213 \mathrm{~km}^{2}$ in the Summer and $349.163 \mathrm{~km}^{2}$ in the dry season. It changed little from 2012 to 2016 . The trend of change in Figure 4.

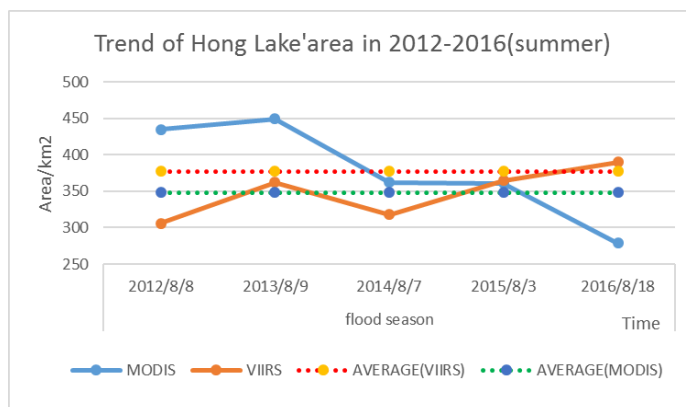

b. Hong Lake flood season area change trend chart

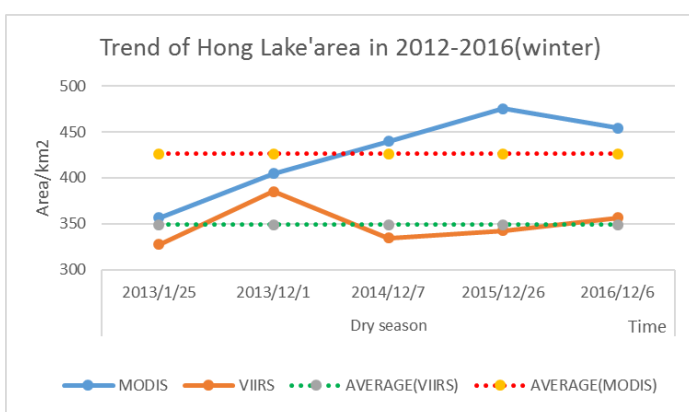

b. Hong Lake dry season area change trend chart

Figure4: Hong Lake' area statistics and trends in 2012 2016(including VIIRS and MODIS), where a and c in the linear use of Office excel software generated linear trend analysis of the line.

\section{CONCLUDING SUMMARY}

VIIRS images as a backup image replace MODIS, due to its free features, and in the future research and application will be more widely used. In this paper, we use some commonly used water extraction methods such as single-band threshold method, spectral relationship method, NDWI and other methods to extract the 2015 and 2016 winter Hong Lake water, try to find a method which is better, more accurate high from the VIIRS image. Contrast found, NDWI is better results. And further use NDWI to 
extract water from Hong Lake waters in summer and winter 2012 2016. In the process of extraction, due to the growth of vegetation around Hong Lake waters in summer will affect the extraction of water. On the basis of $N D W I$, we combined with $N D V I$ for vegetation extraction, so we get two areas, plus two areas get the final water area. In the comparison of the extracted waters, the average area of Hong Lake waters is about $350 \mathrm{~km}^{2}$, which is not very different from that of Sun Chuang's study in 2009. This shows that after people realized the present situation of Hong Lake area, protection measures have been effective. In the study of the status quo and the major problems of Chinese lakes by Yang Guishan and others, with the development of society, the quantity, area and distribution of Chinese lakes have changed significantly and faced with the decrease of lake shrinking and storage capacity. Water quality declines and eutrophication aggravated, biodiversity reduction and ecological degradation, river and lake water and ecological barrier and lake coast and over-exploitation of the lake and other issues, triggering a series of ecological and environmental consequences, seriously affecting the daily life of the river basin residents and economic sustainable development. The use of remote sensing images to study lakes can reflect the changes of the lake objectively and provide decision-making basis for lake governance and protection.

\section{REFERENCES}

Carl F.Schueler, Thomas F. Lee, Steven D.Miller.mVIIRS constant spatial-resolution advantages[J]. International Journal of Remote Sensing, 2013, 34(16):5761-5777.

Dang Wei. Information Extraction and Analysis of River Wetland Based on Remote Sensing and GIS [J]; Journal of China

Deng Hongbing. Study on the Evolution of Jianghan Lake Group and the Sustainable Development of Lake Area [D]. East China Normal University, 2004.

Feng Jingang, Zeng Xiao-dong, Wen Feng. Status and countermeasures of Honghu wetland protection and management [J]. Forestry Science and Technology of Hubei, 2014, 43 (1): 39 42.

Jiang Liguang, Yao Zhijun, Liu Zhaofei, et al. Review of Remote Sensing Research on Dynamic Change of Lakes [J]. Remote Sensing Technology and Application, 2013, 28 (5): 807-814.

Ke Changqing. A review of monit0ring lake environment change by means of remote sensing[J]. Acta Scientology and Oceanology, 2004 (4): 81-86.

Li Qiang, Su Fenzhen, Wang Wenyue. Research on Oil and Gas Platform Extraction Technology Based on VIIRS Data [J] Journal of Earth Information Science, 2017, 19 (3): 398-406.

Ling Chengxing, Research on extracting coastal wetlands water information using composition CIWI water index, 2010, 19 (2): 152. (In Chinese with English abstract) [J]. Journal of Yangtze River Basin Resources and Environment, 2010, 19 (2): 152.

Liu. Why NDWI threshold varies in delineating water body from multit-emporal images[J]. 2012:4375-4378.

Liu Xinhong. Hong Lake water area reduction reasons and impact [J]. South Agriculture, 2014 (10X): 108-109.
Su Chenglin, Su Lin, Chen Liangfu, et al. NPP VIIRS data inversion of aerosol optical thickness [J]. Journal of Remote Sensing, 2015, 19 (6): 977-982.

Sun Chuang, Wang Hongzhi, Li Rendong, et al. Detection of water use change of Honghu Lake based on remote sensing image group [J]. Journal of Jianghan University (Natural Science Edition), 2009, 37 (2): 65-70.

Wen Xiongfei, Cai Bin, Chen Beqing, et al. Research on remote sensing surveillance of water body in Honghu Lake based on Landsat satellite data [J]. People's Yangtze, 2012, 43 (8) 43-47.

Xia Lang, Mao Kepiao, Sun Zhewen, et al. Cloud detection application on NPP VIIRS [J]. China Environmental Science, 2014, 34 (3): 574-580.

Xia Shuang, Ruan Renzong, Yan Meichun. Study on Water Information Extraction Method Based on TM Image [J]. Journal of Nanjing Forestry University, 2012, 36 (4): 29-35.

$\mathrm{Xu}$ Hanqiu. A Study on Information Extraction of Water Body with the Modified Normalized Difference Water Index (MNDW I) [J]. Journal of Remote Sensing, 2005, 9 (5): 589-595.

Yang Guishan, Ma Ronghua, Zhang Lu, et al. The present situation and major problems and protection strategies of Chinese lakes [J]. Lakes Science, 2010, 22 (6): 799-810.

Yildirim H, Ozel M E, Radberger R, et al. Long term monitoring of land use changes of means of remote sensing and GIS[J]. Allgemeine Forst Und Jagdzeitung, 2002, 173(1):15-19.

Zhang Baolin, Jia Ruichen, Zhang Qian, et al.Study on the change of water area in Darrener Lake based on remote sensing [J]. Journal of Soil and Water Conservation, 2011, 18 (6): 196199.

Revised June 2017 